\title{
EDITORS’ INTRODUCTION
}

\author{
BRAD WEISS \\ College of William and Mary \\ (iD https:/ / orcid.org/0000-0002-3795-0064 \\ HEATHER PAXSON \\ Massachusetts Institute of Technology \\ (iD https: / / orcid.org/0000-0002-8429-5429 \\ CHRISTOPHER NELSON \\ University of North Carolina at Chapel Hill \\ (iD) https:// orcid.org/0000-0002-3293-3185
}

What is your vision for Cultural Anthropology?

The three of us are often asked this question as the incoming editors of this storied publication. Our answer is simple: we don't have one. This can be a surprising or even confusing response to our interlocutors. We imagine this is because authors and readers generally assume that editors - who, it is true, exercise their judgment in bringing articles to publication — must be guided by their own topical interests and theoretical preferences, if not personal tastes. This assumption is undoubtedly compounded by our work on behalf of Cultural Anthropology, a journal highly regarded for its distinctive voice and its concerted efforts to make a real difference in the world of anthropology and interdisciplinary scholarship more broadly. But rather than view our editorship as an opportunity to forge a new path through the thicket of anthropological scholarship, we honestly feel that the task and privilege of our editorial collaborative is just that: collaboration. 
In reading manuscripts submitted to the journal over the past fourteen months, we have encountered a wealth of fascinating topics and trends, concepts and concerns that we could never have anticipated, let alone solicited, when we began our editorial work in January 2018. We have been continuously impressed by the range of work we have received from scholars around the world, from doctoral candidates to emeritus professors. We have been equally gratified by the generosity and thoughtfulness of our editorial board and of the reviewers whom they recommend to us weekly. All of this is a testament to the efforts of our predecessors in stewarding a publication to which a very wide readership and prospective authorship feels so strongly attached. Every bit as important has been the indispensable work of our editorial staff, managing editor Marcel LaFlamme and editorial assistant Jessica Lockrem, as well as the leadership and member support of the Society for Cultural Anthropology, the section of the American Anthropological Association that remains committed to publishing an open-access journal and to investing in the scholarly infrastructure that makes this possible.

For its first five years as an open-access title, Cultural Anthropology was published in a custom content management system that had been developed to showcase the Society's dynamic web content and was then retrofitted as a journal publishing platform. This issue marks the migration of the journal to Open Journal Systems (OJS), a purpose-built open-source platform that has long powered our submission and review processes. When a major upgrade to OJS was released in 2016, we saw an opportunity to align ourselves with an active, values-driven developer community while retaining a sense of aesthetic distinctiveness. Financial support from one of our institutions, the College of William and Mary, allowed us to build out the functionality for presenting our Curated Collections - thematic portals into the Cultural Anthropology backfiles - and thereby to offer this feature to the almost 10,000 other journals around the world that also use OJS. In some ways, the pendulum of the Society's publishing program is swinging away from bespoke systems and processes toward new forms of interdependency. We see this shift as an investment in Cultural Anthropology's sustainability, even as we are determined to safeguard the capacity for experimentation that all of us value.

Our vision, then, is to remain true to the legacy of expanding scholarly innovation and inclusion that has been entrusted to us. To do so, we aim to work with the always interesting material submitted to us, helping authors to realize their visions of their scholarship in ways that will spark the most compelling and expansive conversations for the future. 